\title{
Interaction of a dinoflagellate neurotoxin with voltage- activated ion channels in a marine diatom
}

\author{
Sheila A Kitchen ${ }^{1}$, Andrea J Bourdelais $^{2}$, Alison R Taylor ${ }^{\text {Corresp. } 1}$ \\ ${ }^{1}$ Department of Biology and Marine Biology, University of North Carolina Wilmington, Wilmington, North Carolina, United States \\ 2 Center for Marine Science, University of North Carolina Wilmington, Wilmington, North Carolina, United States \\ Corresponding Author: Alison R Taylor \\ Email address: taylora@uncw.edu
}

Background. The potent neurotoxins produced by the harmful algal bloom species Karenia brevis are activators of sodium voltage-gated channels (VGC) in animals, resulting in altered channel kinetics and membrane hyperexcitability. Recent biophysical and genomic evidence supports widespread presence of homologous sodium $\left(\mathrm{Na}^{+}\right)$and calcium $\left(\mathrm{Ca}^{2+}\right)$ permeable VGCs in unicellular algae, including marine phytoplankton. We therefore hypothesized that VGCs of these phytoplankton may be an allelopathic target for waterborne neurotoxins produced by $K$. brevis blooms that could lead to ion channel dysfunction and disruption of signaling in a similar manner to animal $\mathrm{Na}^{+} \mathrm{VGCs.}$

Methods. We examined the interaction of brevetoxin-3 (PbTx-3), a K. brevis neurotoxin, with the $\mathrm{Na}^{+} / \mathrm{Ca}^{2+} \mathrm{VGC}$ of the non-toxic diatom Odontella sinensis using electrophysiology. Single electrode current- and voltage- clamp recordings from 0 . sinensis in the presence of PbTx-3 were used to examine the toxin's effect on voltage gated $\mathrm{Na}^{+} / \mathrm{Ca}^{2+}$ currents. In silico analysis was used to identify the putative $\mathrm{PbTx}$ binding site in the diatoms. We identified $\mathrm{Na}^{+} / \mathrm{Ca}^{2+} \mathrm{VCG}$ homologs from the transcriptomes and genomes of 12 diatoms, including three transcripts from 0 . sinensis and aligned them with site- 5 of $\mathrm{Na}^{+}$ VGCs, previously identified as the PbTx binding site in animals.

Results. Up to $1 \mu \mathrm{M}$ PbTx had no effect on diatom resting membrane potential or membrane excitability. The kinetics of fast inward $\mathrm{Na}^{+} / \mathrm{Ca}^{2+}$ currents that underlie diatom action potentials were also unaffected. However, the peak inward current was inhibited by 33\%, delayed outward current was inhibited by $25 \%$, and reversal potential of the currents shifted positive, indicating a change in permeability of the underlying channels. Sequence analysis showed a lack of conservation of the PbTx binding site in diatom VGC homologs, many of which share molecular features more similar to single-domain bacterial $\mathrm{Na}^{+} / \mathrm{Ca}^{2+}$ VGCs than the 4-domain eukaryote channels.

Discussion. Although membrane excitability and the kinetics of action potential currents were unaffected, the permeation of the channels underlying the diatom action potential was significantly altered in the presence of PbTx-3. However, at environmentally relevant concentrations the effects of $\mathrm{PbTx}$ - on diatom voltage activated currents and interference of cell signaling through this pathway may be limited. The relative insensitivity of phytoplankton VGCs may be due to divergence of site 5 (the putative PbTx binding site), and in some cases, such as $O$. sinensis, resistance to toxin effects may be because of evolutionary loss of the 4-domain eukaryote channel, while retaining a single domain bacterial-like VGC that may substitute in the generation of fast action potentials. 
1 Interaction Of a Dinoflagellate Neurotoxin With Voltage-ACtivated CuRRents

2 in A Marine Diatom

3

4 Sheila A. Kitchen ${ }^{1,3}$, Andrea J. Bourdelais ${ }^{2}$, Alison R. Taylor ${ }^{1}$

5

6 1. Department of Biology and Marine Biology, University of North Carolina Wilmington,

7 Wilmington, North Carolina, United States of America, 2. Center for Marine Science, University

8 of North Carolina Wilmington, Wilmington, North Carolina, United States of America, 9

10 Corresponding Author: Alison R. Taylor

11 Tel: (910) 962-2176

12 Email: taylora@uncw.edu

13

14 3. Current address: Department of Biology, Pennsylvania State University, University Park, 15 Pennsylvania, United States of America 


\section{ABSTRACT:}

Background. The potent neurotoxins produced by the harmful algal bloom species Karenia brevis are activators of sodium voltage-gated channels (VGC) in animals, resulting in altered channel kinetics and membrane hyperexcitability. Recent biophysical and genomic evidence supports widespread presence of homologous sodium $\left(\mathrm{Na}^{+}\right)$and calcium $\left(\mathrm{Ca}^{2+}\right)$ permeable VGCs in unicellular algae, including marine phytoplankton. We therefore hypothesized that VGCs of these phytoplankton may be an allelopathic target for waterborne neurotoxins produced by $K$. brevis blooms that could lead to ion channel dysfunction and disruption of signaling in a similar manner to animal $\mathrm{Na}^{+}$VGCs.

Methods. We examined the interaction of brevetoxin-3 (PbTx-3), a K. brevis neurotoxin, with the $\mathrm{Na}^{+} / \mathrm{Ca}^{2+} \mathrm{VGC}$ of the non-toxic diatom Odontella sinensis using electrophysiology. Single electrode current- and voltage- clamp recordings from $O$. sinensis in the presence of PbTx-3 were used to examine the toxin's effect on voltage gated $\mathrm{Na}^{+} / \mathrm{Ca}^{2+}$ currents. In silico analysis was used to identify the putative PbTx binding site in the diatoms. We identified $\mathrm{Na}^{+} / \mathrm{Ca}^{2+} \mathrm{VCG}$ homologs from the transcriptomes and genomes of 12 diatoms, including three transcripts from $O$. sinensis and aligned them with site-5 of $\mathrm{Na}^{+} \mathrm{VGCs}$, previously identified as the $\mathrm{PbTx}$ binding site in animals.

Results. Up to $1 \mu \mathrm{M}$ PbTx had no effect on diatom resting membrane potential or membrane excitability. The kinetics of fast inward $\mathrm{Na}^{+} / \mathrm{Ca}^{2+}$ currents that underlie diatom action potentials were also unaffected. However, the peak inward current was inhibited by $33 \%$, delayed outward current was inhibited by $25 \%$, and reversal potential of the currents shifted positive, indicating a change in permeability of the underlying channels. Sequence analysis showed a lack of conservation of the PbTx binding site in diatom VGC homologs, many of which share molecular features more similar to single-domain bacterial $\mathrm{Na}^{+} / \mathrm{Ca}^{2+} \mathrm{VGCs}$ than the 4-domain eukaryote channels.

Discussion. Although membrane excitability and the kinetics of action potential currents were unaffected, the permeation of the channels underlying the diatom action potential was significantly altered in the presence of $\mathrm{PbTx}-3$. However, at environmentally relevant concentrations the effects of $\mathrm{PbTx}$ - on diatom voltage activated currents and interference of cell signaling through this pathway may be limited. The relative insensitivity of phytoplankton VGCs may be due to divergence of site 5 (the putative $\mathrm{PbTx}$ binding site), and in some cases, such as 
49 O. sinensis, resistance to toxin effects may be because of evolutionary loss of the 4-domain

50 eukaryote channel, while retaining a single domain VGC that can substitute in the generation of 51 fast action potentials.

52 
54

55

56

57

58

59

60

61

62

63

64

65

66

67

68

69

70

\section{INTRODUCTION}

Periodic algal blooms of the toxic dinoflagellate, Karenia brevis (C.C. Davis, 1948; G. Hansen \& Moestrup, 2000), have been reported since the mid-1600s in the Gulf of Mexico, predominately along the west coast of Florida (Steidinger, 2009). These blooms result in massive marine animal mortalities (Hackett et al., 2004; Pierce \& Henry, 2008; Landsberg, Flewelling \& Naar, 2009) and also present problems for humans, where toxin exposure is a major public health concern because exposure though consumption of contaminated shellfish or inhalation of aerosolized toxins can cause adverse neurological and respiratory symptoms associated with neurotoxic shellfish poisoning (Smayda, 1997; Van Dolah, 2000; Fleming et al., 2011). The associated economic losses (Hoagland et al., 2002) and increased frequency and duration of harmful algal blooms (HABs) (Paerl \& Whitall, 1999; Van Dolah, 2000) has led to increased efforts to understand the factors that regulate algal toxin production, bloom dynamics and toxin susceptibility (Van Dolah, 2000; Pierce \& Henry, 2008; Henrichs, Hetland \& Campbell, 2015; Weisberg et al., 2016). In spite of these efforts, the functional role for PbTx production by $K$. brevis remains poorly understood.

The potent, lipophilic neurotoxins produced by $K$. brevis are classified by their polyether ladder backbone chemical structures, PbTx-A (Pbtx-1, -7, -10) or PbTx-B (PbTx-2, -3, -6, -9). PbTx-1 and PbTx-2 are the intracellular parent compounds and most toxic, while the less toxic extracellular derivatives are produced through intermediary metabolism and environmental turnover (Pierce \& Henry, 2008). The biosynthetic pathway for brevetoxin production is yet to be resolved, although cytosolic (Van Dolah et al., 2013), plastidic (López-Legentil et al., 2010; Monroe et al., 2010; Van Dolah et al., 2013), modular and single domain polyketide synthases (Van Dolah et al., 2017) may be involved in production of these secondary metabolites.

Intracellular concentrations of PbTx can vary widely with bloom age, salinity, nutrient, light and clone type making bloom toxicity difficult to predict (Brown et al., 2006; Lekan \& Tomas, 2010; Corcoran, Richardson \& Flewelling, 2014). However, it only takes pM to nM concentrations of these potent toxins to be lethal in some vertebrate models (Baden, 1989; Pierce \& Henry, 2008). Nevertheless, it is unlikely that the potent effect of $\mathrm{PbTx}$ on metazoans represents the primary functional role for toxin production. 
83

84

85

86

87

88

Several studies have addressed whether these algal secondary metabolites underpin a chemically mediated allelopathy against grazers. Ingestion of toxic $K$. brevis cells by pelagic copepods (Breier \& Buskey, 2007; Cohen, Tester \& Forward, 2007; Hong et al., 2012; Lauritano et al., 2013), rotifers (Kubanek, Snell \& Pirkle, 2007), benthic amphipods and urchins (Sotka et al., 2009) have variable effects on zooplankton growth or fecundity, with little evidence of an anti-predation mechanism. Studies have also investigated whether PbTxs confer an allelopathic advantage against other ecologically relevant targets such as co-occurring phytoplankton. Culture experiments have provided evidence for a wide range of interactions, from resistance to sublethality of phytoplankton grown with K. brevis or exposed to their purified toxins (Freeberg, Marshall \& Heyl, 1978; Kubanek et al., 2005; Myers et al., 2008; Prince, Myers \& Kubanek, 2008; Prince et al., 2008; Poulson et al., 2010; Poulson-Ellestad et al., 2014a; Poulson-Ellestad et al., 2014b). For example, Freeberg, Marshall and Heyl (1978) reported species-specific effects of K. brevis culture filtrates or cell extracts on cell growth of 18 different phytoplankton species encompassing four different phyla. As a follow up to this study, Kubanek et al. (2005) also observed species-specific effects on phytoplankton competitors when exposed to live K. brevis or their filtrates, bulk extracts or purified toxins. Most notable was the reduced growth of the diatoms Amphora sp., Asterionellopis glacialis, Rhizosolenia cf. setigera, Skeletonema costatum and Thalassiosira sp., and dinoflagellates Akashiwo sanquinea, Peridinium sp., and Prorocentrum minimum in the presence of live K. brevis, but not necessarily with purified PbTxs. On the other hand, other competitors such as the diatom Odontella aurita and chlorophyte Chlorella capsulata were unaffected by live K. brevis; however, their response to purified PbTx was not tested (Kubanek et al., 2005). Additional experiments have reported that extracts from natural blooms contain a mixture of other allelopathic compounds that reduce growth of some phytoplankton competitors more than the derivative forms of the extracellular PbTxs (Prince, Myers \& Kubanek, 2008; Poulson et al., 2010; Poulson-Ellestad et al., 2014b). Although many interactions have been reported with PbTx derivatives or other allelopathic compounds, the underlying cellular mechanisms remain unknown.

In the case of animals, binding assays with $\mathrm{PbTx}$ show the primary molecular target is $\mathrm{Na}^{+}$VGCs (Poli, Mende \& Baden, 1986; Gawley et al., 1992) critical for propagation of electrical signals in the neuromuscular system (Baden, 1989; Gawley et al., 1992; Trainer, Baden \& Catterall, 1994; Baden, Rein \& Gawley, 1998; Cestèle \& Catterall, 2000; Baden et al., 2005). 
114 These metazoan $\mathrm{Na}^{+}$channels belong to a large eukaryote family of 4-domain VGCs (D1-D4), 115 each composed of six transmembrane spanning segments (6TM) designated S1-S6 (Cestèle \& 116 Catterall, 2000; Anderson, Roberts-Misterly \& Greenberg, 2005). The S4 segment of each 117 domain contains positively charged arginine residues that act as voltage sensors for channel 118 activation (Yang \& Horn, 1995). Voltage dependent inactivation is controlled by a short 119 intracellular loop connecting D3 and D4 that blocks the pore during depolarization (Armstrong 120 \& Bezanilla, 1977; West et al., 1992). The binding site of PbTx was first characterized in $\mathrm{Na}^{+}$ 121 VGC, type II $\left(\mathrm{Na}_{\mathrm{v}} 1.2\right)$ that are broadly distributed in neurons and highly sensitive to another 122 neurotoxin, tetrodotoxin (Trainer, Baden \& Catterall, 1994; Lee \& Ruben, 2008). The PbTx 123 receptor site 5 has two components, one region on the intracellular $\alpha$-subunit (D1, S6) and one 124 on the extracellular $\alpha$-subunit (D4, S5) (Trainer, Baden \& Catterall, 1994). The molecular model 125 proposed (Trainer, Baden \& Catterall, 1994) suggests that the hydrophobic PbTx interacts with 126 both sites simultaneously by binding to the transmembrane interface and traversing the pore 127 region of the $\mathrm{Na}^{+}$channel. Specific PbTx interaction with metazoan $\mathrm{Na}^{+}$VGCs results in: 1. a 128 negative shift of channel activation (Huang, Wu \& Baden, 1984), 2. inhibition of channel 129 inactivation (Huang, Wu \& Baden, 1984; Poli, Mende \& Baden, 1986; Ulbricht, 2005), and 3. an 130 increase in $\mathrm{Na}^{+}$influx associated with prolonged membrane depolarization (Atchison et al., 1986; Sheridan \& Adler, 1989). However, binding affinity and alteration of channel kinetics by $\mathrm{PbTx}$ varies depending on the derivative form of the toxin, tissue type exposed and species specificity (Bottein Dechraoui \& Ramsdell, 2003; Bottein Dechraoui, Wacksman \& Ramsdell, 134 2006).

Genomic and biophysical studies demonstrate that rapid membrane excitability associated with the $\mathrm{Na}^{+} / \mathrm{Ca}^{2+} \mathrm{VGCs}$, evolved prior to the divergence of Metazoa with representative 4-domain VGCs found in several unicellular protists including phytoplankton (Armbrust et al., 2004; Verret et al., 2010; Liebeskind, Hillis \& Zakon, 2011; Moran et al., 2015). Evidence for the presence of such VGCs in several phytoplankton groups includes the dinoflagellates (Eckert \& Sibaoka, 1968; Ryan, Pepper \& Campbell, 2014), coccolithophores (Taylor \& Brownlee, 2003), and diatoms (Gradmann \& Boyd, 1995; Taylor, 2009). The marine

142 diatom Odontella sinensis (Greville 1866; Grunow 1884) exhibits spontaneous and evoked 143 action potentials with similar kinetic and pharmacological characteristics closely resembling 144 $\mathrm{Na}^{+} / \mathrm{Ca}^{2+}$ VGC mediated action potentials of animals (Taylor, 2009). We therefore hypothesized 
145

146

147

148

149

150

151

152

153

154

155

156

157

158

159

160

161

162

163

164

165

166

167

168

169

170

171

172

173

174

175

that PbTx interacts with VGCs underlying phytoplankton membrane excitability in such a way as to disrupt sensory or signaling processes, thereby conferring a competitive advantage for the toxin producer. In order to test this hypothesis, we examined the effects of $\mathrm{PbTx}-3$, the most abundant extracellular form of PbTx (Lekan \& Tomas, 2010), on the voltage-activated $\mathrm{Na}^{+} / \mathrm{Ca}^{2+}$ current previously characterized in the diatom O. sinensis (Taylor, 2009).

\section{MATERIALS AND METHODS}

\section{Phytoplankton cultures}

O. sinensis (PLY606), obtained from Plymouth Culture Collection at the Marine Biological Association, UK, was batch cultured in $50 \mathrm{ml}$ polystyrene vented flask (Cellstar, Fisher) with autoclaved, $0.2 \mu \mathrm{m}$ filtered seawater enriched with $\mathrm{f} / 2$ nutrients, Guillard's vitamins and $2 \mathrm{mM} \mathrm{NaHCO}_{3}$ (Guillard \& Ryther, 1962). Cultures were maintained at $15^{\circ} \mathrm{C}$ under 12:12 day:night cycle with $100 \mu \mathrm{mol} \mathrm{m}^{-2} \mathrm{~s}^{-1}$ light. Cells in mid-exponential phase were typically 50$100 \mu \mathrm{m}$ long and 30-50 $\mu \mathrm{m}$ wide. All experiments were conducted using cells collected during exponential growth phase of the batch culture at a cell density of $\sim 10^{5} \mathrm{ml}^{-1}$ determined by cell counts with a haemocytometer.

\section{Single electrode current and voltage clamp recordings and analysis}

Single electrode current and voltage clamp experiments were conducted using methods previously described for $O$. sinensis (Taylor, 2009). Microelectrodes were fabricated from GC150F-10 thick walled borosilicate glass capillaries (Harvard Apparatus, Kent, UK) using a Flaming-Brown Micropipette Puller P-97 (Sutter Instruments, Petaluma, USA) and coated with beeswax to reduce stray capacitance. Electrodes were filled with $1 \mathrm{M} \mathrm{KCl}$ and those with tip resistance between 8-14 M $\Omega$ were used. Electrodes were inserted into the headstage of an Axoclamp 900A amplifier (Axon Instruments, Union City, USA) mounted on a Sutter MP285 motorized micromanipulator (Sutter Instruments, Petaluma, USA) that was attached to an inverted microscope (Nikon Diaphot, Nikon, USA)

The single electrode current clamp and voltage clamp experiments were controlled and acquired with a PC connected to the amplifier via a Digidata 1200A interface (Axon Instruments, Union City, USA). An external gain was applied prior to A-D conversion using a DC amplifier (LBF-100B, Warner Instrument Corps, Hamden, USA). Data were acquired using Clampex 
176 v10.2 and all analysis was conducted offline with Clampfit v10.2 software (Axon Instruments, 177 Union City, USA).

178 We observed that $O$. sinensis takes up fluorescently labeled PbTx in membranes and lipid 179 bodies (Kramer, Kitchen \& Taylor, unpublished), indicating that these lipophilic molecules 180 interact with diatom cell membranes and can accumulate. A $1 \mu \mathrm{M}$ concentration of PbTx-3 was

181

182

183

184

185

186

187

188

189

190

191

192

193

194

195

196

197

198

199

200

201

202

203

204

205

206

used in all electrophysiological experiments because $400 \mathrm{nM}$ labeled-PbTx-B showed significant staining in $30 \mathrm{~min}$. The higher concentration of unreacted PbTx-3 therefore ensured any effect should be detected during a typical recording of about 30-45 min and falls within the range (500 $\mathrm{nM}-2.8 \mu \mathrm{M}$ ) of the original experiments that described the interaction of PbTx with $\mathrm{Na}^{+} \mathrm{VGCs}$ (Huang, Wu \& Baden, 1984; Atchison et al., 1986; Sheridan \& Adler, 1989). Purified PbTx-3 was provided by Dr. D.G. Baden, University of North Carolina Wilmington Center for Marine Science, prepared as a $1 \mathrm{mM}$ stock solution in DMSO and stored at $-20{ }^{\circ} \mathrm{C}$. A working solution was made up in ASW to a concentration of $1 \mu \mathrm{M}$ immediately prior to experiments. Lidocaine (Sigma, St. Louis, USA), a known inhibitor of $O$. sinensis action potentials (Taylor, 2009), was prepared as a $1 \mathrm{M}$ stock in ASW with a working solution of $1 \mathrm{mM}$ in ASW and stored at $4{ }^{\circ} \mathrm{C}$. $O$. sinensis cells were plated onto poly-L-lysine coated $35 \mathrm{~mm}$ glass bottom dishes (MatTek Corporation, Ashland, USA) with a final bath volume of $1 \mathrm{ml}$ and perfused with ASW from a gravity fed reservoir $\left(1.5 \mathrm{ml} \mathrm{min}^{-1}\right)$. For both the current and voltage clamp experiments, initial control recordings were conducted under ASW perfusion. The perfusion was then stopped and a bolus addition of $\mathrm{ASW}(n=7), 1 \mu \mathrm{M} \mathrm{PbTx}-3(n=14)$ or $1 \mathrm{mM}$ lidocaine $(n=4)$ was added to a final bath volume of $1 \mathrm{ml}$ and the cells incubated for at least $15 \mathrm{~min}$ before acquiring recordings in the presence of test compound. Post-treatment washes by perfusion with fresh ASW were applied for an additional 15-30 min. All experiments were conducted at room temperature $\left(20-22^{\circ} \mathrm{C}\right)$.

\section{Bioinformatic analysis of the $\mathrm{PbTx}-3$ binding site}

At the time of this study, two diatom genome assemblies were available, one of the polar centric diatom Thalassiosira pseudonana (class Mediophyceae) and raphid pennate diatom Phaeodactylum tricornutum (class Bacillariophyceae, (Armbrust et al., 2004; Bowler et al., 2008)). In addition ten diatom transcriptomes (see Table S1) were available either through Marine Microbial Eukaryote Transcriptome Sequencing Project (Keeling et al., 2014) deposited 
207 at iMicrobe (http://imicrobe.us, accessed June 14, 2015) or National Center for Biotechnology

208 Information (NCBI), of which five belong to the class Bacillariophyceae, one belongs to class

209 Coscinodiscophyceae (although the current phylogenetic placement of Attheya sp. is unresolved

210 (Parks, Wickett \& Alverson, 2017)) and four belong to the class Mediophyceae, including $O$.

211 sinensis and its sister species $O$. aurita.

212 To determine the conservation of the predicted PbTx binding sites (Trainer, Baden \&

213 Catterall, 1994) in diatoms and other photosynthetic protists, we searched available sequence

214 resources to find homologous 1-domain or 4-domain VGCs in diatoms and other representative

215 taxa, BLAST searches (BLASTp or tBLASTn version 2.2.31+) (Altschul et al., 1990) were

216 performed with 4-domain VGCs protein sequences from a squid (Heterololigo bleekeri; NCBI:

217 BAA03398.1), a rat (Rattus norvegicus $\mathrm{Na}_{\mathrm{v}} 1.4$; NCBI: AAA41682.1) and the diatom $T$.

218 pseudonana (NCBI: XP_002289136.1; previously reported in Verret et al. (2010) and Moran et

219 al. (2015)), and 1-domain VGC protein from the bacterium Bacillus halodurans C-125 (NCBI:

220 BAB05220.1) against NCBI or local BLAST databases (Table S1) built from the diatom

221 transcriptomes. Significant thresholds for sequence similarity were set to an E-value $<1 \mathrm{e}^{-10}$ in

222 the large database (NCBI) or a bit-score $\geq 50$ in the small databases (local). Multiple sequence

223 alignments were constructed from the top scoring sequences using MUSCLE (Edgar, 2004) in

224 the software package Geneious v8.0.3 (Kearse et al., 2012). The voltage sensor, selectivity-filter

225 and inactivation gate are well-characterized structural motifs of $\mathrm{Na}^{+}$VGCs (West et al., 1992;

226 Tsushima, Li \& Backx, 1997; Catterall, 2000) that were used as features to manually curate the

227 orthologs from the sequence alignments. The final set of sequences with hallmark features of a

$228 \mathrm{Na}^{+} \mathrm{VGC}$ are listed in Table S1. The PbTx-3 binding site originally identified in $\mathrm{Na}_{\mathrm{v}} 1.2$ (NCBI:

229 CAA27287.1) was used for sequence comparison to the $\mathrm{Na}^{+}$VGCs found in this study (Table

$230 \mathrm{~S} 1$ ). The $\mathrm{NaChBac}$ channel is predicted to form a tetramer of four identical domains (Ren et al.,

231 2001). To compare the PbTx binding site to 1-domain VGCs found in O. sinensis, we

232 concatenated the single domain of the protein sequence \#4108 into a hypothetical homotetramer.

233 Visualization of protein structure between bacterial NaChBac (NCBI: BAB05220.1), diatoms $O$.

234 sinensis (iMicrobe: \#4108), P. tricornutum (NCBI: XP_002186055.1) and T. pseudonana

235 (NCBI: XP_002289136.1 and XP_002287819.1), dinoflagellate K. brevis (iMicrobe: SPI

236 287987) and $\mathrm{Na}_{\mathrm{v}} 1.2$ (NCBI: CAA27287.1) was made using Domain Graph (DOG) v2.0 (Ren et

237 al., 2009). 


\section{Statistical analysis}

Quantitative electrophysiological parameters are presented as the mean \pm SE. Data for

241

242

243

244

245

246

247

248

249

250

251

252

253

254

255

256

257

258

259

260

261

262

263

264

265

266

267

268

control and PbTx-3 treatments were analyzed using a paired Student's T-test with an alpha level of $\leq 0.05$ chosen to represent significant differences.

\section{RESULTS}

Diatom resting membrane potential and membrane excitability are unaffected by $\mathrm{PbTx}-3$

Under steady state conditions, $O$. sinensis cells exhibited endogenous membrane oscillations with spontaneous firing of rapid action potentials (50-100 ms duration) when the threshold voltage was reached $(n=24$ cells, Fig. 1A and B). Long periods of very stable negative membrane potentials were also observed in some cells (Fig. 1C). As with animal $\mathrm{Na}^{+} \mathrm{VGCs}$, the diatom action potentials comprised a fast rising phase followed by a slower hyperpolarization phase (Fig. S1). The cells either elicited single or several repetitive action potential spikes (Fig. S1A and B). In all cells examined, whether exhibiting quiescent or oscillating membrane potentials, injections of $1 \mathrm{nA}$ current over $10 \mathrm{~ms}$ evoked action potentials (Fig. S1C).

Bolus additions of ASW represented a control treatment and did not induce any deviation from the steady state recordings for up to $15 \mathrm{~min}(n=4$ cells, Fig. $1 \mathrm{~A})$. Additions of $1 \mu \mathrm{M} \mathrm{PbTx}-$ 3 for $15 \mathrm{~min}$ also had no significant effect on free-running resting membrane potential in $O$. sinensis $(n=12$ cells). This lack of response in the presence of PbTx-3 was consistent regardless of the pattern of membrane potential exhibited by any given cell, as cells exhibiting both spontaneous action potentials ( $n=7$ cells) and stable negative membrane voltages $(n=5$ cells $)$ are represented in the PbTx-3 treatments (Fig. $1 \mathrm{~B}$ and $\mathrm{C}$ ).

\section{PbTx-3 partially blocks $O$. sinensis $\mathrm{Na}^{+} / \mathrm{Ca}^{2+}$ currents}

Voltage clamp experiments were conducted to investigate whether more subtle effects on VGCs were induced by interaction with $\mathrm{PbTx}$. A depolarizing voltage-step protocol from a holding potential of $-100 \mathrm{mV}$ to $50 \mathrm{mV}$ in $10 \mathrm{mV}$ increments was used to activate $\mathrm{Na}^{+} / \mathrm{Ca}^{2+}$ currents (Fig. 2A). The control bolus additions of ASW ( $n=7$ cells) yielded no change in fast inward current or slower delayed outward current after a 15 min treatment (Fig. 2A). Addition of $1 \mu \mathrm{M}$ PbTx-3 caused a $33.6 \pm 6.6 \%$ decrease in average peak $\mathrm{Na}^{+} / \mathrm{Ca}^{2+}$ current amplitude from - 
$26919.7 \pm 2.6 \mathrm{nA}$ to $-13.0 \pm 2.0 \mathrm{nA}(n=14$ cells, Student's T-test $p<0.001)$ after a 15 min treatment

270 (Fig. 2A and B). Neither voltage activation nor voltage of the peak current was significantly

271 affected by PbTx-3 over $15 \mathrm{~min}(-47.2 \pm 3.8 \mathrm{mV}$ and $-45.7 \pm 3.0 \mathrm{mV}$ for control and PbTx-3

272 treatments, respectively; Fig. 2C). In addition to the suppressed peak inward current, $\mathrm{PbTx}-3$

273 caused a distinct shift in the reversal potential of the inward current from $15.0 \pm 2.6 \mathrm{mV}$ to 32.2

$274 \pm 5.8 \mathrm{mV}(n=14$ cells, Student's T-test $p<0.01)$ suggesting a change in the selectivity of the 275 underlying ion channels (Fig. 2C). Washout with toxin-free ASW perfusion on PbTx-3 treated

276 cells showed limited recovery after $15 \mathrm{~min}$ (peak amplitude $-14.9 \pm 2.4 \mathrm{nA}, n=10$ cells, data not

277 shown), and partial recovery after $30 \mathrm{~min}$ (peak amplitude $-17.6 \pm 6.1, n=4$ cells, data not

278 shown). Analysis of the delayed outward current showed a $25 \%$ decrease in current amplitude

279 from $13.1 \pm 1.1 \mathrm{nA}$ to $9.98 \pm 0.76 \mathrm{nA}(n=14$ cells, Student's T-test $p<0.001$, Fig. $2 \mathrm{C})$.

280 Treatment with $1 \mathrm{mM}$ lidocaine, known to block animal and diatom $\mathrm{Na}^{+}$currents, caused

281 a $61.7 \pm 7.2 \%(n=4$ cells, data not shown $)$ inhibition in the evoked $\mathrm{Na}^{+} / \mathrm{Ca}^{2+} \mathrm{VGC}$ of $O$.

282 sinensis which is consistent with previous data and confirmed that the perfusion protocol was

283 sufficient to deliver toxin treatments during electrophysiological experiments (Taylor, 2009).

284

285

286

287

288

289

\section{Negligible effects of PbTx-3 on diatom VGC kinetics}

PbTxs have been shown to modify both activation and inactivation properties of animal

$\mathrm{Na}^{+}$channels (Huang, Wu \& Baden, 1984; Jeglitsch et al., 1998). To investigate the effect of

PbTx-3 on the activation kinetics of the $O$. sinensis $\mathrm{Na}^{+} / \mathrm{Ca}^{2+} \mathrm{VGCs}$, conductance was calculated according to Strachan et al. (1999), normalized to peak conductance and fitted with a Boltzmann function in order to determine the half activation voltage $\left(\mathrm{V}_{\mathrm{h}}\right)($ Fig. 3A). No significant change in $\mathrm{V}_{\mathrm{h}}$ was observed between the control $(-58.5 \pm 1.0 \mathrm{mV})$ and PbTx-3 treatments $(-57.9 \pm 1.8 \mathrm{mV}$, Student's T-test $p>0.05)$.

The effects of PbTx-3 on the inactivation of $O$. sinensis $\mathrm{Na}^{+} / \mathrm{Ca}^{2+}$ current were

294

295

296

297

298

299 determined using a voltage protocol of $50 \mathrm{~ms}$ pre-pulses from $-100 \mathrm{mV}$ to $-15 \mathrm{mV}$ in $5 \mathrm{mV}$ increments applied before a depolarizing pulse selected to evoke a full inward current. The peak evoked current values were normalized to the maximum peak and plotted against pre-pulse voltage before fitting a Boltzmann function (Fig. 3B). A small but significant positive shift in the half-inactivation voltage $\left(\mathrm{V}_{\text {inact }}\right)$ was observed in the presence of PbTx-3 $(-65.7 \pm 0.5 \mathrm{mV})$ compared to the control $\mathrm{V}_{\text {inact }}(-69.4 \pm 0.5 \mathrm{mV}, n=14$ cells, Student's T-test $p<0.05)$. A double 
300 pulse protocol was used to further characterize the possible effects of $\mathrm{PbTx}-3$ on the inactivation

301 properties of these channels (Fig. 3C). No significant change in recovery from inactivation was

302 observed in PbTx-3 treatments (control $\tau=5.1 \mathrm{~ms} \pm 0.4$ and PbTx-3 $\tau=6.1 \mathrm{~ms} \pm 0.4$, Student's

303 T-test $p>0.05$, Fig. 3C).

304

305

306

307

Brevetoxin binding site 5 analysis

308 ciliates and Perkinsus) and stramenopiles (diatoms, brown algae, and oomycetes), putative VGCs were recovered from BLAST similarity searches (Table S1). Unexpectedly, most diatom

309

310

311

312

313

314

315

316

317

318

319

320

321

322

323

324

325

326

327

328

329

330 sequences found using this approach, including $O$. sinensis, were 1-domain VGCs with greatest similarity to the bacterial $\mathrm{Na}^{+}$VGC NaChBac (TableS1, Fig. 4A and S2) (Ren et al., 2001). Only one diatom, $T$. pseudonana, appeared to possess both 1 -domain and 4-domain $\mathrm{Na}^{+} / \mathrm{Ca}^{2+} \mathrm{VGCs}$ (Fig. 4A and B).

To investigate whether a previously characterized $\mathrm{PbTx}-3$ binding site could be found in the putative $\mathrm{Na}^{+} / \mathrm{Ca}^{2+}$ VGCs of SAR-group (Stramenopiles, Alveolates and Rhizaria), a multiple sequence alignment was used (Fig. 4C). The characterized site 5 in metazoan $\mathrm{Na}^{+} \mathrm{VGCs}$ comprises two 18-20 amino acid segments, the first directly following the conserved S6 of domain 1 (D1), and the second, follows S5 of domain 4 (D4) (Fig. 4A) (Trainer, Baden \& Catterall, 1994). Among all of the representative eukaryotic 4-domain VGC sequences and concatenated sequence of 1-domain VGC from O. sinensis (\#4108) into a 4-domain hypothetical homotetramer, D1- S6 and D4- S5 are moderately conserved across all taxa (Fig. 4C). However, while vertebrates showed strong conservation of site 5 compared to the mammalian $\mathrm{Na}_{\mathrm{v}} 1.2$ channel, divergence of site 5 was apparent in invertebrate 4-domain VGCs of the squid $H$. bleekeri and the sea anemone Exaiptasia pallida, as well as in the choanoflagellate Monosiga brevicollis. The representative taxa from the SAR-group showed little sequence conservation at this characterized site 5 .

\section{DISCUSSION}

In squid, crayfish, frog and mammalian neuronal models it is known that $100 \mathrm{nM}$ to $1 \mu \mathrm{M}$ $\mathrm{PbTx}$ interacts with 4 domain $\mathrm{Na}^{+}$VGCs causing hyperexcitability resulting in rapid firing of action potentials (Kim et al., 1975; Westerfield et al., 1977; Huang, Wu \& Baden, 1984). The 
331 underlying cause is a $-10 \mathrm{mV}$ shift in voltage-dependent activation of $\mathrm{Na}^{+} \mathrm{VGCs}$ (Atchison et al., 332 1986; Sheridan \& Adler, 1989) and delayed inactivation (Huang, Wu \& Baden, 1984; Baden, 333 Rein \& Gawley, 1998; Jeglitsch et al., 1998). In the present study, O. sinensis $\mathrm{Na}^{+} / \mathrm{Ca}^{2+}$ VGCs 334 did not exhibit these characteristic changes in function when exposed to $1 \mu \mathrm{M} \mathrm{PbTx}-3$, but did 335 exhibit an interaction that resulted in reduced permeation and a positive shift in reversal 336 potential. The reduction in the peak inward $\mathrm{Na}^{+} / \mathrm{Ca}^{2+}$ current in $O$. sinensis was similar to that 337 observed in squid axons (Huang, Wu \& Baden, 1984), but was not accompanied by significant 338 changes in kinetics of the current or membrane hyperexcitability. It has been suggested that 339 PbTxs may alter subconductance states reflecting a protein conformation in which the flow of 340 ions through the channel pore is less efficient (Jeglitsch et al., 1998). The slower outward 341 rectifying current of $O$. sinensis associated with the repolarizing phase of the action potential was 342 also inhibited by the $\mathrm{PbTx}-3$, which indicates that at these relatively high concentrations, 343 inhibitory interactions of PbTx may not be channel specific.

The PbTx-3-induced positive shift in the reversal potential of $\mathrm{Na}^{+} / \mathrm{Ca}^{2+}$ currents in $O$.

345 sinensis implies a change in ion selectivity in favor of $\mathrm{Ca}^{2+}$ ions. The $O$. sinensis $\mathrm{VGCs}$ that 346 underlie the diatom action potential are known to be permeable to both $\mathrm{Na}^{+}$and $\mathrm{Ca}^{2+}$ (Taylor, 347 2009), presumably coupling membrane excitability with intracellular signaling processes through 348 changes in cytoplasmic $\mathrm{Ca}^{2+}$ (Falciatore et al., 2000; Vardi et al., 2006). PbTx-3 interaction at the 349 pore of the channel may directly or allosterically alter channel selectivity, which would result in 350 altered $\mathrm{Ca}^{2+}$ influx and associated intracellular $\mathrm{Ca}^{2+}$ dynamics (LePage, Baden \& Murray, 2003).

351 However, the permeability shift of the whole cell currents could also be attributed to $\mathrm{PbTx}$ 352 inhibition of a subpopulation of $\mathrm{Na}^{+} / \mathrm{Ca}^{2+}$ channels with lower $\mathrm{Ca}^{2+}$ permeability that would 353 otherwise contribute to the whole channel current. PbTx inhibition and altered reversal of $354 \mathrm{Na}^{+} / \mathrm{Ca}^{2+}$ whole cell currents has not to our knowledge been previously documented for animal $355 \mathrm{Na}^{+}$selective currents, and appears to be a unique feature of PbTx interaction with the diatom $356 \mathrm{Na}^{+}$VGC. Given the key role that intracellular $\left[\mathrm{Ca}^{2+}\right]_{\text {cyt }}$ plays in mediating stress responses of 357 phytoplankton, including programmed cell death (see Bidle (2015) and references therein) it will 358 be interesting to determine whether PbTx interactions with phytoplankton $\mathrm{Na}^{+} / \mathrm{Ca}^{2+}$ channels 359 affects intracellular $\mathrm{Ca}^{2+}$ dynamics at steady state or in response to biotic or abiotic stressors. 360 The lack of effect of PbTx-3 on the kinetics of activation and inactivation of the $O$. 361 sinensis $\mathrm{Na}^{+} / \mathrm{Ca}^{2+}$ currents points to a novel interaction of these molecules with the underlying 
362 algal VGCs. This is consistent with the absence of hyperexcitability observed in the presence of

$363 \mathrm{PbTx}-3$ that would be expected if voltage dependent activation and inactivation were shifted

364

365

366

367

368

369

370

371

372

373

374

375

376

377

378

379

380

381

382

383

384

385

386

387

388

389

390

391

392 negative. Overall, $\mathrm{PbTx}-3$ effects were observed on permeation and peak amplitude of diatom currents, but were not accompanied by significant changes to their kinetic properties. We conclude that $O$. sinensis VGCs may be affected by $\mathrm{PbTx}-3$ interactions, albeit with reduced efficacy compared to PbTx-sensitive metazoan channels (Westerfield et al., 1977; Huang, Wu \& Baden, 1984; Jeglitsch et al., 1998). Under normal bloom conditions levels of PbTxs in surface waters are rarely observed greater than 30 to $80 \mathrm{nM}$ (Backer et al., 2005; Tester et al., 2008), and although longer term effects or species-specific responses (Kubanek et al., 2005; Poulson et al., 2010; Poulson-Ellestad et al., 2014a) cannot be ruled out, it seems unlikely, at least in the case of $O$. sinensis, that VGCs and interference of diatom action potential mediated processes are significantly impacted by waterborne exposure to toxins produced during blooms of K. brevis. This is consistent with culture-based experiments on a sister species of $O$. sinensis from the Gulf of Mexico, Odontella aurita, that did not experience reduced cell growth in the presence of live K. brevis but instead significantly inhibited growth of K. brevis (Kubanek et al., 2005; PoulsonEllestad et al., 2014b).

The potential for $\mathrm{PbTx}-3$ to interact with diatom $\mathrm{Na}^{+} / \mathrm{Ca}^{2+} \mathrm{VGCs}$ was investigated by sequence comparison of the PbTx binding site of 4-domain $\mathrm{Na}^{+} / \mathrm{Ca}^{2+} \mathrm{VGCs}$ among a range of taxa including representatives from the SAR-group. There is no clear conservation of amino acid residues across site- 5 in this group, although there are more conserved residues in the extracellular portion of site-5. In animal $\mathrm{Na}^{+}$VGCs, that are PbTx-sensitive, biophysical evidence shows the toxin interacts with the pore domain at both the intracellular and extracellular side, thereby affecting permeation and inactivation kinetics (Huang, Wu \& Baden, 1984). The lack of conservation of site 5 in the SAR-group 4-domain VGCs implies PbTx interactions are likely compromised which could explain their relative insensitivity to this toxin. Nevertheless, given the flexibility of the $\mathrm{PbTx}$ molecule, it is not unreasonable to speculate that novel biophysical outcomes of PbTx may occur as a result of binding to the more conserved extracellular receptor site, and interaction with alternate sites within the $\alpha$-subunit of the channel protein altering $\mathrm{Na}^{+} \mathrm{VGC}$ function (Trainer, Baden \& Catterall, 1994). Interestingly, our analysis of site- 5 also showed poor homology in the D1T6 part of site- 5 of the squid H. bleekeri $\mathrm{Na}^{+}$ VGC homolog although previous biophysical studies have used H. bleekeri axons as a model 
393

394

395

396

397

398

399

400

401

402

403

404

405

406

407

408

409

410

411

412

413

414

415

416

417

418

419

420

421

422

423

system to demonstrate the highly specific biophysical effects of $\mathrm{PbTx}$ on $\mathrm{Na}^{+} \mathrm{VGC}$ function (Kim et al., 1975; Westerfield et al., 1977; Huang, Wu \& Baden, 1984). Therefore, the D4T5 region of site- 5 may be the most important residues for $\mathrm{PbTx}$ interaction. It is also possible that the amino acid residues in rat brain $\mathrm{Na}_{\mathrm{v}} 1.2$ from which site- 5 was determined may not represent the only PbTx interaction site, especially in VGC's of lower invertebrates and other eukaryotes. An alternative explanation for relative insensitivity of $O$. sinensis $\mathrm{Na}^{+} / \mathrm{Ca}^{2+}$ currents to $\mathrm{PbTx}$ is that this species appears to lack a 4-domain VGC (Fig. 4), as has also been reported for the genome of the pennate diatom Phaeodactylum tricornutum (Verret et al., 2010). An unexpected finding of the present study was the prevalence of expressed single-domain $\mathrm{Na}^{+} / \mathrm{Ca}^{2+}$ VGCs (similar to single domain bacterial channels, $\mathrm{NaChBac}$ ) in diatom transcriptomes. Only one putative 4-domain $\mathrm{Na}^{+} / \mathrm{Ca}^{2+} \mathrm{VGC}$ was found in the genome of centric diatom $T$. pseudonana that was previously described (Taylor, 2009; Moran et al., 2015). This is in marked contrast to other algal lineages including chlorophytes such as Chlamydomonas (Fujiu et al., 2009) and Micromonas (Verret et al., 2010), the multicellular stramenopile Ectocarpus (Verret et al., 2010), and in K. brevis itself that reportedly has seven 4-domain VGCs predicted from its transcriptome (Ryan, Pepper \& Campbell, 2014) that each bear the $\mathrm{Ca}^{2+}$ selective permeability motif (EEEE, Fig. 4A.) suggesting an important role in $\mathrm{Ca}^{2+}$ transport and signaling.

Single-domain bacterial $\mathrm{Na}^{+}$VGCs comprise six transmembrane helices (S1-6) with a voltage sensor of arginine residues within S4 and pore loop between S5 and S6. These bacterial VGCs have been shown to be involved in motility, chemotaxis, $\mathrm{pH}$ homeostasis and metabolic growth (Ito et al., 2004; DeCaen et al., 2014). They form homotetramers and when expressed in heterologous systems show many of the biophysical features of eukaryote 4-domain VGCs (Ren et al., 2001; Koishi et al., 2004; Scheuer, 2014). The large 4-domain VGCs of eukaryotes form two major groups, the $\mathrm{Ca}^{2+}$ and $\mathrm{Na}^{+} \mathrm{VGCs}$, that were proposed to have arisen from gene duplication and undergone functional diversification (Strong, Chandy \& Gutman, 1993; Cestèle \& Catterall, 2000). Shared structural features between eukaryotic and prokaryotic VGCs lead to the hypothesis that VGCs ultimately originated from the ancestral one-domain prokaryote channel (Anderson, Roberts-Misterly \& Greenberg, 2005), although, recent phylogenetic studies indicate independent origins (Verret et al., 2010; Liebeskind, Hillis \& Zakon, 2013). However, in both bacterial and eukaryote VGCs the high field strength (HFS) residue in the pore loop between S5 and S6 determines ion selectivity and more recent structural and functional analyses 
424 suggests additional sites downstream in the ascending pore loop may also play critical roles in

425 ion permeation (Fig. S2) (Ren et al., 2001; Liebeskind, Hillis \& Zakon, 2013; DeCaen et al.,

426 2014; Stephens et al., 2015). In vertebrates the $\mathrm{Na}^{+}$selectivity filter HFS sites surrounding the

427 pore domain creates a heterotetrameric DEKA motif (Fig. 4A), but in bacteria the motif is

428 composed of glutamate residues from each of the four monomers similar to the $\mathrm{Ca}^{2+} \mathrm{EEEE}$ filter

429 (Finol-Urdaneta et al., 2014). Even though the EEEE selectivity motif is more similar to

430 eukaryotic 4-domain $\mathrm{Ca}^{2+} \mathrm{VGCs}$, bacterial $\mathrm{NaChBac}$ are strongly selective for $\mathrm{Na}^{+}$over $\mathrm{K}^{+}$or

$431 \mathrm{Ca}^{2+}$ (Yue et al., 2002; Koishi et al., 2004; Scheuer, 2014). Recent studies show that point-

432 mutation of the bacterial $\mathrm{Na}^{+}$selectivity filter (TLESW $\rightarrow$ TLDSW) can induce non-selective

433 cation transport (DeCaen et al., 2014; Finol-Urdaneta et al., 2014; Tang et al., 2014). The single

434 domain VGCs found in diatoms possess a mixture of $\mathrm{Na}^{+}$selective and non-selective filter motifs

435 (Fig. 4B), which could explain their permeability to both $\mathrm{Na}^{+}$and $\mathrm{Ca}^{2+}$ ions (Taylor, 2009). The

436 widespread presence of single domain VGCs in diatoms raises a number of interesting questions

437 including; whether they functionally substitute for 4-domain channels in generating diatom

438 action potentials, and what selective pressures led to apparent loss of 4-domain $\mathrm{Na}^{+} / \mathrm{Ca}^{2+} \mathrm{VGCs}$

439 in diatoms.

440

441

CONCLUSIONS

442

In summary, $O$. sinensis membrane potential did not demonstrate the characteristic

443 hyperexcitabilty associated with $\mathrm{PbTx}$ exposure. However, evoked voltage activated currents that

444 underlie the diatom action potential were partially inhibited and accompanied by an apparent

445 shift in the ion selectivity that favors $\mathrm{Ca}^{2+}$ influx. Nevertheless, the apparent lack of 4-domain

446 eukaryotic VGCs in O. sinensis and poor conservation of the PbTx binding site could underlie

447 this unique interaction. Given the relatively weak effect of PbTx, O. sinensis VGCs and cell

448 signaling are likely to be relatively insensitive to $\mathrm{PbTx}$ at environmentally relevant

449 concentrations. Further examination of sympatric phytoplankton species, specifically those with

450 documented allelopathic interactions (Kubanek et al., 2005; Poulson et al., 2010) is necessary to

451 elucidate PbTx interactions with diverse algal VGCs and their signaling functions.

452

453 ACKNOWLEDGEMENTS 
We would like to thank J. Craig Bailey and Carmelo Tomas for their helpful discussions

455

456

457

458

459

460

461

462

463

464

465

466

467

468

469

470

471

472

473

474

475

476

477

478

479

480

481

482 and editorial comments during manuscript preparation. We would also like to thank Elizabeth Elliot for technical assistance on the project.

\section{FIGURE LEGENDS}

Figure 1. Effect of PbTx-3 on O. sinensis membrane potential. Representative traces show free-running membrane potential monitored over 15 min following additions of (A) ASW and $(\mathrm{B}, \mathrm{C}) 1 \mu \mathrm{M}$ PbTx-3 indicated by arrows. No significant change in pattern of membrane potential was observed ( $n=4$ and 12 cells for control and treatments, respectively) for either cells exhibiting spontaneous oscillations (A, B) or quiescent membrane potential (C).

Figure 2. Effects of PbTx-3 on O. sinensis voltage activated currents. (A) Representative ion currents evoked in response to depolarizing voltage clamp pulses under control conditions, after 15 min treatment of bolus ASW ( $n=7$ cells tested) and after treatment with $1 \mu \mathrm{M} \mathrm{PbTx}-3$ for 15 min showing a clear decline in both peak inward and delayed outward currents $(n=14$ cells tested). (B) Detail of fast inactivating inward current evoked by voltage clamp pulse from -100 $\mathrm{mV}$ to $-60 \mathrm{mV}$ before and after $1 \mu \mathrm{M} \mathrm{PbTx}-3$ perfusion. (C) Combined current-voltage plot for $\mathrm{PbTx}$ perfusion experiments in which average peak inward current was plotted as a function of membrane voltage in the absence (black circles) and presence of $1 \mu \mathrm{M} \mathrm{PbTx}-3$ (orange circles), and peak outward current in the absence (black triangles) and presence of $1 \mu \mathrm{M} \mathrm{PbTx}-3$ (orange triangles). $n=14$ experiments. Standard error bars are indicated.

\section{Figure 3. Activation and inactivation properties of diatom $\mathrm{Na}^{+} / \mathrm{Ca}^{2+}$ currents in the} presence of PbTx-3. (A) Voltage activation was determined by calculating the peak $\mathrm{Na}^{+} / \mathrm{Ca}^{2+}$ conductance $(\mathrm{g})$ for each voltage pulse and normalized to the maximum conductance. The resulting $\mathrm{g}-\mathrm{V}$ values were fitted to a Boltzmann distribution. Half activation voltage $\left(\mathrm{V}_{\mathrm{h}}\right.$, the voltage stimulus that evoked $50 \%$ of the peak current) was not significantly affected by $1 \mu \mathrm{M}$ PbTx-3. (B) Steady state voltage inactivation was determined using a series of depolarizing voltage pre-pulses from a holding voltage of $-100 \mathrm{mV}$ were applied before evoking maximal inward currents by a test pulse to $-60 \mathrm{mV}$. The average peak currents in response to test pulses were normalized to the maximum peak current and fitted to a Boltzmann curve. Half inactivation voltage $\left(\mathrm{V}_{\text {inact }}\right)$ was the pre-pulse voltage at which half the peak current was suppressed. There 
483 was a small but significant ( $p<0.05$, Students T-test) positive shift in the inactivation in the

484 presence of PbTx-3 compared to controls. (C) Recovery from inactivation was measured using a

485

486

487

488

489

490

491

492

493

494

495

496

497

498

499

500

501

502

503

504

505

506

507

508

509

510

511

512 double pulse protocol under control conditions in which the first voltage evoked a maximal inward $\mathrm{Na}^{+} / \mathrm{Ca}^{2+}$ current followed by a variable time interval $(\Delta \mathrm{ms})$, after which a second depolarization pulse was applied. The peak response to the second voltage clamp pulse after a 2 ms delay was less than $10 \%$ of the peak, demonstrating the majority of VCGs were inactivated. Delay of 10-20 ms was generally required for the current to be fully recovered. The same recovery from inactivation protocol was applied to the same cell after $1 \mu \mathrm{M} \mathrm{PbTx}-3$ treatment showed a similar pattern of recovery although overall a decreased peak current amplitude as demonstrated in Fig. 2. Capacity transients are removed from the current traces for clarity. A recovery from inactivation plot where the second peak current response is expressed as a $\%$ of the first and plotted against the pulse time interval. Control (black circles) and $1 \mu \mathrm{M} \mathrm{PbTx}-3$ (orange circles) curves were fit with an exponential with no significant difference in the time constant. In all experimental trials $(n=14)$ the standard error bars are indicated.

\section{Figure 4. Sequence analysis of diatom $\mathrm{Na}^{+} / \mathrm{Ca}^{2+}$ VGCs and $\mathrm{PbTx}$ binding site. (A)} Representative single domain $\mathrm{Na}^{+} / \mathrm{Ca}^{2+}$ VGCs were selected from bacteria (NaChBac), and the diatoms $O$. sinensis, P. tricornutum and T. pseudonana. Four-domain channels are represented by the diatom $T$. pseudonana, dinoflagellate $K$. brevis, and mammalian $\mathrm{Na}_{\mathrm{v}} 1.2$. The major transmembrane spanning domains colored in blue. The site of the high field strength residue within the selectivity filter is indicated by a letter above each domain. In the 4-domain VGCs, the inactivation gate is indicated and the PbTx binding site previously identified in $\mathrm{Na}_{\mathrm{v}} 1.2$ are highlighted in orange. (B) A multiple sequence alignment of the diatom 1-domain channels obtained by BLAST searches with the bacterial channel $\mathrm{NaChBac}$. The selectivity filter is indicated in light blue and the high field strength residue in teal. (C) Multiple sequence alignment of eukaryote 4-domain $\mathrm{Na}^{+}$VGCs highlighting the two $\mathrm{PbTx}-3$ binding regions characterized by Trainer et al. (1994). Conserved residues are labeled in orange (80-100\% similarity) and yellow (80-60\% similarity). Highly conserved residues of the upstream transmembrane segments are colored based on similarity using the Blosum62 score matrix (Henikoff \& Henikoff, 1992), where darker shades of grey are more similar. Sequences were obtained from NCBI and iMicrobe databases with further details provided in Table S1. 


\section{REFERENCES}

514 Altschul SF, Gish W, Miller W, Myers EW, and Lipman DJ. 1990. Basic local alignment search

515

516

517

518

519

520

521

522

523

524

525

526

527

528

529

530

531

532

533

534

535

536

537

538

539

540

541

542 tool. Journal of Molecular Biology 215:403-410. 10.1016/S0022-2836(05)80360-2

Anderson PAV, Roberts-Misterly J, and Greenberg RM. 2005. The evolution of voltage-gated sodium channels: were algal toxins involved? Harmful Algae 4:95-107. 10.1016/j.hal.2003.12.007

Armbrust EV, Berges JA, Bowler C, Green BR, Martinez D, Putnam NH, Zhou S, Allen AE, Apt KE, Bechner M, Brzezinski MA, Chaal BK, Chiovitti A, Davis AK, Demarest MS, Detter JC, Glavina T, Goodstein D, Hadi MZ, Hellsten U, Hildebrand M, Jenkins BD, Jurka J, Kapitonov VV, Kroger N, Lau WWY, Lane TW, Larimer FW, Lippmeier JC, Lucas S, Medina M, Montsant A, Obornik M, Parker MS, Palenik B, Pazour GJ, Richardson PM, Rynearson TA, Saito MA, Schwartz DC, Thamatrakoln K, Valentin K, Vardi A, Wilkerson FP, and Rokhsar DS. 2004. The genome of the diatom Thalassiosira pseudonana: Ecology, evolution, and metabolism. Science 306:79-86.

10.1126/science. 1101156

Armstrong CM, and Bezanilla F. 1977. Inactivation of the sodium channel. II. Gating current experiments. The Journal of General Physiology 70:567-590. 10.1085/jgp.70.5.567

Atchison WD, Luke VS, Narahashi T, and Vogel SM. 1986. Nerve membrane sodium channels as the target site of brevetoxins at neuromuscular junctions. British Journal of Pharamcology 89:731-738. 10.1111/j.1476-5381.1986.tb11177.x

Backer LC, Kirkpatrick B, Fleming LE, Cheng YS, Pierce R, Bean JA, Clark R, Johnson D, Wanner A, and Tamer R. 2005. Occupational exposure to aerosolized brevetoxins during Florida red tide events: effects on a healthy worker population. Environmental Health Perspectives 113:644-649. 10.1289/ehp.7502

Baden D, Bourdelais AJ, Jacocks H, Michelliza S, and J. N. 2005. Natural and derivative brevetoxins: historical background, multiplicity, and effects. Environmental Health Perspectives 113:621-625. 10.1289/ehp.7499

Baden D, Rein K, and Gawley R. 1998. Marine toxins: How they are studied and what they can tell us. In: Cooksey KE, ed. Molecular Approaches to the Study of the Ocean. London: Springer, Dordrecht. 
543 Baden DG. 1989. Brevetoxins-unique polyether dinoflagellate toxins. FASEB Journal 3:1807-

544

545

546

547

548

549

550

551

552

553

554

555

556

557

558

559

560

561

562

563

564

565

566

567

568

569

570

571

572

573

1817.

Bidle KD. 2015. The molecular ecophysiology of programmed cell death in marine phytoplankton. Annual Review of Marine Science 7:341-375. 10.1146/annurev-marine010213-135014

Bottein Dechraoui M-Y, and Ramsdell JS. 2003. Type B brevetoxins show tissue selectivity for voltage-gated sodium channels: comparison of brain, skeletal muscle and cardiac sodium channels. Toxicon 41:919-927.

Bottein Dechraoui M-Y, Wacksman JJ, and Ramsdell JS. 2006. Species selective resistance of cardiac muscle voltage gated sodium channels: Characterization of brevetoxin and ciguatoxin binding sites in rats and fish. Toxicon 48:702-712.

Bourdelais AJ, Campbell S, Jacocks H, Naar J, Wright JLC, Carsi J, and Baden DG. 2004. Brevenal is a natural inhibitor of brevetoxin action in sodium channel receptor binding assays. Cellular and Molecular Neurobiology 24:553-563.

10.1023/B:CEMN.0000023629.81595.09

Bowler C, Allen AE, Badger JH, Grimwood J, Jabbari K, Kuo A, Maheswari U, Martens C, Maumus F, Otillar RP, Rayko E, Salamov A, Vandepoele K, Beszteri B, Gruber A, Heijde M, Katinka M, Mock T, Valentin K, Verret F, Berges JA, Brownlee C, Cadoret JP, Chiovitti A, Choi CJ, Coesel S, De Martino A, Detter JC, Durkin C, Falciatore A, Fournet J, Haruta M, Huysman MJJ, Jenkins BD, Jiroutova K, Jorgensen RE, Joubert Y, Kaplan A, Kroger N, Kroth PG, La Roche J, Lindquist E, Lommer M, Martin-Jezequel V, Lopez PJ, Lucas S, Mangogna M, McGinnis K, Medlin LK, Montsant A, Secq M-POL, Napoli C, Obornik M, Parker MS, Petit J-L, Porcel BM, Poulsen N, Robison M, Rychlewski L, Rynearson TA, Schmutz J, Shapiro H, Siaut M, Stanley M, Sussman MR, Taylor AR, Vardi A, von Dassow P, Vyverman W, Willis A, Wyrwicz LS, Rokhsar DS, Weissenbach J, Armbrust EV, Green BR, Van de Peer Y, and Grigoriev IV. 2008. The Phaeodactylum genome reveals the evolutionary history of diatom genomes. Nature 456:239-244. 10.1038/nature07410

Breier CF, and Buskey EJ. 2007. Effects of the red tide dinoflagellate, Karenia brevis, on grazing and fecundity in the copepod Acartia tonsa. Journal of Plankton Research 29:115-126. 10.1093/plankt/fbl075 
574 Brown AFM, Dortch Q, Dolah FMV, Leighfield TA, Morrison W, Thessen AE, Steidinger K,

575 Richardson B, Moncreiff CA, and Pennock JR. 2006. Effect of salinity on the

576 distribution, growth, and toxicity of Karenia spp. Harmful Algae 5:199-212.

$577 \quad$ 10.1016/j.hal.2005.07.004

578 Catterall WA. 2000. From ionic currents to molecular mechanisms: the structure and function of 579 voltage-gated sodium channels. Neuron 26:13-25. 10.1016/S0896-6273(00)81133-2

580 Cestèle S, and Catterall WA. 2000. Molecular mechanisms of neurotoxin action on voltage-gated 581 sodium channels. Biochimie 82:883-892. 10.1016/S0300-9084(00)01174-3

Cohen JH, Tester PA, and Forward RB, Jr. 2007. Sublethal effects of the toxic dinoflagellate 583

584 Karenia brevis on marine copepod behavior. Journal of Plankton Research 29:301-315. 10.1093/plankt/fbm016

Corcoran AA, Richardson B, and Flewelling LJ. 2014. Effects of nutrient-limiting supply ratios 586 on toxin content of Karenia brevis grown in continuous culture. Harmful Algae 39:334341. 10.1016/j.hal.2014.08.009

DeCaen PG, Takahashi Y, Krulwich TA, Ito M, and Clapham DE. 2014. Ionic selectivity and 589 590 thermal adaptations within the voltage-gated sodium channel family of alkaliphilic Bacillus. eLife 3:e04387. 10.7554/eLife.04387

591

592

593

594

595

596

597

598

599

600

601

602

603

Eckert R, and Sibaoka T. 1968. The flash triggering action potential of the luminescent dinoflagellate Noctiluca. The Journal of General Physiology 52:258-282. 10.1085/jgp.52.2.258

Edgar RC. 2004. MUSCLE: multiple sequence alignment with high accuracy and high throughput. Nucleic Acids Research 32:1792-1797. 10.1093/nar/gkh340

Falciatore A, d'Alcala MR, Croot P, and Bowler C. 2000. Perception of environmental signals by a marine diatom. Science 288:2363-2366. 10.1126/science.288.5475.2363

Finol-Urdaneta RK, Wang Y, Al-Sabi A, Zhao C, Noskov SY, and French RJ. 2014. Sodium channel selectivity and conduction: Prokaryotes have devised their own molecular strategy. The Journal of General Physiology 143:157-171. 10.1085/jgp.201311037

Fleming LE, Kirkpatrick B, Backer LC, Walsh CJ, Nierenberg K, Clark J, Reich A, Hollenbeck J, Benson J, Cheng YS, Naar J, Pierce R, Bourdelais AJ, Abraham WM, Kirkpatrick G, Zaias J, Wanner A, Mendes E, Shalat S, Hoagland P, Stephan W, Bean J, Watkins S, 
604

605

606

607

608

609

610

611

612

613

614

615

616

617

618

619

620

621

622

623

624

625

626

627

628

629

630

631

632

633

Clarke T, Byrne M, and Baden DG. 2011. Review of Florida red tide and human health effects. Harmful Algae 10:224-233. 10.1016/j.hal.2010.08.006

Freeberg LA, Marshall A, and Heyl M. 1978. Interrelationships of Gymnodinium breve (Florida red tide) within the phytoplankton community. In: Taylor DL, and Seliger HH, eds. Toxic Dinoflagellate Blooms. 1978 ed. New York: Elsevier, 139-144.

Fujiu K, Nakayama Y, Yanagisawa A, Sokabe M, and Yoshimura K. 2009. Chlamydomonas CAV2 encodes a voltage- dependent calcium channel required for the flagellar waveform conversion. Current Biology 19:133-139. 10.1016/j.cub.2008.11.068

Gawley RE, Rein KS, Kinoshita M, and Baden DG. 1992. Binding of brevetoxins and ciguatoxin to the voltage-senstive sodium-channel and conformational analysis of brevetoxin-B. Toxicon 30:780-785. 10.1016/0041-0101(92)90014-V

Gradmann D, and Boyd CM. 1995. Membrane voltage of marine-phytoplankton, measure in the diatom Coscinodiscus radiatus. Marine Biology 123:645-650. 10.1007/BF00349107

Guillard RRL, and Ryther JH. 1962. Studies of marine planktonic diatoms I. Cyclotella nana Hustedt and Detonula confervacea Cleve. Canadian Journal of Microbiology 8:229-239. 10.1139/m62-029

Hackett JD, Anderson DM, Erdner DL, and Bhattacharya D. 2004. Dinoflagellates: A remarkable evolutionary experiment. American Journal of Botany 91:1523-1534. 10.3732/ajb.91.10.1523

Henikoff S, and Henikoff JG. 1992. Amino acid substitution matrices from protein blocks. Proceedings of the National Academy of Sciences 89:10915-10919.

Henrichs DW, Hetland RD, and Campbell L. 2015. Identifying bloom origins of the toxic dinoflagellate Karenia brevis in the western Gulf of Mexico using a spatially explicit individual-based model. Ecological Modelling 313:251-258. doi.org/10.1016/j.ecolmodel.2015.06.038

Hoagland P, Anderson D, Kaoru Y, and White A. 2002. The economic effects of harmful algal blooms in the United States: Estimates, assessment issues, and information needs. Estuaries and Coasts 25:819-837. 10.1007/bf02804908

Hong J, Talapatra S, Katz J, Tester PA, Waggett RJ, and Place AR. 2012. Algal toxins alter copepod feeding behavior. PloS One 7:e36845. 10.1371/journal.pone.0036845 
634 Huang JM, Wu CH, and Baden DG. 1984. Depolarizing action of a red-tide dinoflagellate 635 brevetoxin on axonal membranes. The Journal of Pharmacology and Experimental 636 Therapeutics 229:615-621.

637 Ito M, Xu H, Guffanti AA, Wei Y, Zvi L, Clapham DE, and Krulwich TA. 2004. The voltage638 gated $\mathrm{Na}+$ channel $\mathrm{NaVBP}$ has a role in motility, chemotaxis, and $\mathrm{pH}$ homeostasis of an 639 alkaliphilic Bacillus. Proceedings of the National Academy of Sciences 101:10566640 10571. 10.1073/pnas.0402692101

Jeglitsch G, Rein K, Baden DG, and Adams DJ. 1998. Brevetoxin-3 (PbTx-3) and its derivatives modulate single tetrodotoxin-sensitive sodium channels in rat sensory neurons. Journal of Pharmacology and Experimental Theraputics 284:516-525.

Kearse M, Moir R, Wilson A, Stones-Havas S, Cheung M, Sturrock S, Buxton S, Cooper A, Markowitz S, Duran C, Thierer T, Ashton B, Meintjes P, and Drummond A. 2012.

646

Keeling PJ, Burki F, Wilcox HM, Allam B, Allen EE, Amaral-Zettler LA, Armbrust EV, 650 Archibald JM, Bharti AK, Bell CJ, Beszteri B, Bidle KD, Cameron CT, Campbell L, 651 652 Caron DA, Cattolico RA, Collier JL, Coyne K, Davy SK, Deschamps P, Dyhrman ST, Edvardsen B, Gates RD, Gobler CJ, Greenwood SJ, Guida SM, Jacobi JL, Jakobsen KS, James ER, Jenkins B, John U, Johnson MD, Juhl AR, Kamp A, Katz LA, Kiene R, Kudryavtsev A, Leander BS, Lin S, Lovejoy C, Lynn D, Marchetti A, McManus G, Nedelcu AM, Menden-Deuer S, Miceli C, Mock T, Montresor M, Moran MA, Murray S, Nadathur G, Nagai S, Ngam PB, Palenik B, Pawlowski J, Petroni G, Piganeau G, Posewitz MC, Rengefors K, Romano G, Rumpho ME, Rynearson T, Schilling KB, Schroeder DC, Simpson AGB, Slamovits CH, Smith DR, Smith GJ, Smith SR, Sosik HM, Stief P, Theriot E, Twary SN, Umale PE, Vaulot D, Wawrik B, Wheeler GL, Wilson WH, Xu Y, Zingone A, and Worden AZ. 2014. The Marine Microbial Eukaryote Transcriptome Sequencing Project (MMETSP): Illuminating the functional diversity of eukaryotic life in the oceans through transcriptome sequencing. PLoS Biology 12:e1001889. 10.1371/journal.pbio.1001889 
664 Kim YS, Mandel LJ, Westerfield M, Padilla GM, and Moore JW. 1975. Effect of Gymondinium 665 breve toxin(s) on frog skin and the giant axon of the squid. Environmental Letters 9:255666 264. $10.1080 / 00139307509435854$

667 Koishi R, Xu H, Ren D, Navarro B, Spiller BW, Shi Q, and Clapham DE. 2004. A superfamily 668 of voltage-gated sodium channels in bacteria. Journal of Biological Chemistry 279:9532669 9538. 10.1074/jbc.M313100200

670 Kubanek J, Hicks MK, Naar J, and Villareal TA. 2005. Does the red tide dinoflagellate Karenia 671 672 brevis use allelopathy to outcompete other phytoplankton? Limnology and Oceanography 50:883-895. 10.4319/10.2005.50.3.0883

673 674 10.4319/10.2007.52.3.1026

676

677

678

679

680

681

Kubanek J, Snell TW, and Pirkle C. 2007. Chemical defense of the red tide dinoflagellate Karenia brevis against rotifer grazing. Limnology and Oceanography 52:1026-1035.

Landsberg JH, Flewelling LJ, and Naar J. 2009. Karenia brevis red tides, brevetoxins in the food web, and impacts on natural resources: Decadal advancements. Harmful Algae 8:598607. 10.1016/j.hal.2008.11.010

Lauritano C, Carotenuto Y, Procaccini G, Turner JT, and Ianora A. 2013. Changes in expression of stress genes in copepods feeding upon a non-brevetoxin-producing strain of the dinoflagellate Karenia brevis. Harmful Algae 28:23-30. 10.1016/j.hal.2013.05.004

682 683

Lee CH, and Ruben PC. 2008. Interaction between voltage-gated sodium channels and the neurotoxin, tetrodotoxin. Channels 2:407-412. 10.4161/chan.2.6.7429

Lekan DK, and Tomas CR. 2010. The brevetoxin and brevenal compostion of three Karenia brevis clones at different salinities and nutriend conditions. Harmful Algae 9:39-47. 10.1016/j.hal.2009.07.004

LePage KT, Baden DG, and Murray TF. 2003. Brevetoxin derivatives act as partial agonists at 688 neurotoxin site 5 on the voltage-gated $\mathrm{Na}+$ channel. Brain Research 959:120-127.

Liebeskind BJ, Hillis DM, and Zakon HH. 2011. Evolution of sodium channles predates the origin of nervous system in animals. Proceedings of the National Academy of Sciences

692 108:9154-9159. 10.1073/pnas.1106363108

Liebeskind BJ, Hillis DM, and Zakon HH. 2013. Independent acquisition of sodium selectivity 694 in bacterial and animal sodium channels. Current Biology 23:948-949. 10.1016/j.cub.2013.09.025 
695 López-Legentil S, Song B, DeTure M, and Baden D. 2010. Characterization and localization of a 696 hybrid non-ribosomal peptide synthetase and polyketide synthase gene from the toxic 697 dinoflagellate Karenia brevis. Marine Biotechnology 12:32-41. 10.1007/s10126-009$6989197-\mathrm{y}$

699 Monroe EA, Johnson JG, Wang Z, Pierce RK, and Van Dolah FM. 2010. Characterization and 700 expression of nuclear-encoded polyketide synthases in the brevetoxin-producing 701 702 703 704 705 706

Parks MB, Wickett NJ, and Alverson AJ. 2017. Signal, uncertainty, and conflict in phylogenomic data for a diverse lineage of microbial eukaryotes (Diatoms, Bacillariophyta). Molecular Biology and Evolution 35:80-93. doi.org/10.1093/molbev/msx268

Pierce RH, and Henry MS. 2008. Harmful algal toxins of the Florida red tide (Karenia brevis): natural chemical stressors in South Florida coastal ecosystems. Ecotoxicology 17:623631. 10.1007/s10646-008-0241-X

Poli MA, Mende TJ, and Baden DG. 1986. Brevetoxins, unique activators of voltage-sensitive sodium channels, bind to specific sites in rat brain synatosomes. Molecular Pharmacology 30:129-135.

Poulson-Ellestad KL, Jones CM, Roy J, Viant MR, Fernández FM, Kubanek J, and Nunn BL. 2014a. Metabolomics and proteomics reveal impacts of chemically mediated competition on marine plankton. Proceedings of the National Academy of Sciences 111:9009-9014. 10.1073/pnas.1402130111 
726 Poulson-Ellestad KL, Mcmillan E, Montoya JP, and Kubanek J. 2014b. Are offshore

727 phytoplankton susceptible to Karenia brevis allelopathy? Journal of Plankton Research

728 36:1344-1356. 10.1093/plankt/fbu064

729 Poulson KL, Sieg RD, Prince EK, and Kubanek J. 2010. Allelopathic compounds of a red tide

730 dinoflagellate have species-specific and context-dependent impacts on phytoplankton.

731 Marine Ecology Progress Series 416:69-78. 10.3354/meps08788

732 Prince EK, Myers TL, and Kubanek J. 2008. Effects of harmful algal blooms on competitors:

733 Allelopathic mechanisms of the red tide dinoflagellate Karenia brevis. Limnology and

$734 \quad$ Oceanography 53:531-541. 10.4319/10.2008.53.2.0531

735 Prince EK, Myers TL, Naar J, and Kubanek J. 2008. Competing phytoplankton undermines

736 allelopathy of a bloom-forming dinoflagellate. Proceedings of the Royal Society B:

737 Biological Sciences 275:2733-2741. 10.1098/rspb.2008.0760

738 Ren DJ, Navarro B, Xu HX, Yue LX, Shi Q, and Clapham DE. 2001. A prokaryotic voltage-

739 gated sodium channel. Science 294:2372-2375. 10.1126/science.1065635

740 Ren J, Wen L, Gao X, Jin C, Xue Y, and Yao X. 2009. DOG 1.0: illustrator of protein domain

$741 \quad$ structures. Cell Research 19:271-273. 10.1038/cr.2009.6

742 Ryan DE, Pepper AE, and Campbell L. 2014. De novo assembly and characterization of the

$743 \quad$ transcriptome of the toxic dinoflagellate Karenia brevis. BMC Genomics 15:888.

$744 \quad 10.1186 / 1471-2164-15-888$

745

746

747

748

749

750

751

752

753

Scheuer T. 2014. Bacterial sodium channels: models for eukaryotic sodium and calcium channels. Voltage Gated Sodium Channels: Springer, Berlin, Heidelberg, 269-291.

Sheridan RE, and Adler M. 1989. The actions of a red tide toxin form Ptychodiscus brevis on single sodium channels in mammalian neuroblastoma cells. FEBS Letters 247:448-452. 10.1016/0014-5793(89)81389-4

Smayda TJ. 1997. Harmful algal blooms: Their ecophysiology and general relevance to phytoplankton blooms in the sea. Limnology and Oceanography 42:1137-1153. 10.4319/1o.1997.42.5_part_2.1137

Sotka EE, McCarty A, Monroe EA, Oakman N, and Van Dolah FM. 2009. Benthic herbivores 754 755 are not deterred by brevetoxins produced by the red tide dinoflagellate Karenia brevis Journal of Chemical Ecology 35:851-859. 10.1007/s10886-009-9658-9 
756 Steidinger KA. 2009. Historical perspective on Karenia brevis red tide research in the Gulf of 757 Mexico. Harmful Algae 8:549-561. 10.1016/j.hal.2008.11.009

758 Stephens RF, Mehta A, Zhorov BS, and Spafford JD. 2015. Alternative forms of selectivity

759

760

761

762

763

764

765

766

767

768

769

770

771

772

773

774

775

776

777

778

779

780

781

782

783

784

785

786

filters and turrets, and the patterning of cysteines in extended loops provide clues to a unique extracellular domain within eukaryotic voltage-gated sodium, calcium, and NALCN channels. Frontiers in Physiology 6. 10.3389/fphys.2015.00153

Strachan LC, Lewis RJ, and Nicholson GM. 1999. Differential actions of pacific ciguatoxin-1 on sodium channel subtypes in mammalian sensory neurons. The Journal of Pharmacology and Experimental Therapeutics 288:379-388.

Strong M, Chandy KG, and Gutman G. 1993. Molecular evolution of voltage-sensitive ion channel genes: on the origins of electrical excitability. Molecular Biology and Evolution $10: 221-242$.

Tang L, El-Din TMG, Payandeh J, Martinez GQ, Heard TM, Scheuer T, Zheng N, and Catterall WA. 2014. Structural basis for $\mathrm{Ca}^{2+}$ selectivity of a voltage-gated calcium channel. Nature 505:56-61. 10.1038/nature12775

Taylor AR. 2009. A fast $\mathrm{Na}^{+} / \mathrm{Ca}^{2+}$ based action potential in a marine diatom. PloS One 4:e4966. 10.1371/journal.pone.0004966

Taylor AR, and Brownlee C. 2003. A novel Cl- inward-rectifying current in the plasma membrane of the calcifying marine phytoplankton Coccolithus pelagicus. Plant Physiology 131:1391-1400. 10.1104/pp.011791

Tester PA, Shea D, Kibler SR, Varnam SM, Black MD, and Litaker RW. 2008. Relationships among water column toxins, cell abundance and chlorophyll concentrations during Karenia brevis blooms. Continental Shelf Research 28:59-72. 10.1016/j.csr.2007.04.007

Trainer VL, Baden DG, and Catterall WA. 1994. Identification of peptide components of the brevetoxin receptor site of rat brain sodium channels. Journal of Biological Chemistry 269:19904-19909.

Tsushima RG, Li RA, and Backx PH. 1997. P-loop flexibility in $\mathrm{Na}^{+}$channel pores revealed by single- and double-cysteine replacements. Journal of General Physiology 110:59-72. 10.1085/jgp.110.1.59

Ulbricht W. 2005. Sodium channel inactivation: molecular determinants and modulation. Physiological Reviews 85:1271-1301. 10.1152/physrev.00024.2004

Peer) reviewing PDF | (2017:11:21903:1:1:NEW 2 Mar 2018) 
787 788

789

790

791

792

793

794

795

796

797

798

799

800

801

802

803

804

805

806

807

808

809

810

811

812

813

814

815

816

817

Van Dolah FM. 2000. Marine algal toxins: Origins, health effects, and their increased occurrence. Environmental Health Perspectives 108:133-141. 10.2307/3454638

Van Dolah FM, Kohli GS, Morey JS, and Murray SA. 2017. Both modular and single-domain Type I polyketide synthases are expressed in the brevetoxin-producing dinoflagellate, Karenia brevis (Dinophyceae). Journal of Phycology 53:1325-1339. 10.1111/jpy.12586

Van Dolah FM, Zippay ML, Pezzolesi L, Rein KS, Johnson JG, Morey JS, Wang Z, and Pistocchi R. 2013. Subcellular localization of dinoflagellate polyketide synthases and fatty acid synthase activity. Journal of Phycology 49:1118-1127. 10.1111/jpy.12120

Vardi A, Formiggini F, Casotti R, De Martino A, Ribalet F, Miralto A, and Bowler C. 2006. A stress surveillance system based on calcium and nitric oxide in marine diatoms. PLoS Biology 4:411-419. 10.1371/journal.pbio.0040060

Verret F, Wheeler G, Taylor AR, Farnham G, and Brownlee C. 2010. Calcium channels in photosynthetic eukaryotes: implications for evolution of calcium-based signalling. New Phytologist 187:23-43. 10.1111/j.1469-8137.2010.03271.x

Weisberg RH, Zheng L, Liu Y, Corcoran AA, Lembke C, Hu C, Lenes JM, and Walsh JJ. 2016. Karenia brevis blooms on the West Florida Shelf: A comparative study of the robust 2012 bloom and the nearly null 2013 event. Continental Shelf Research 120:106-121. doi.org/10.1016/j.csr.2016.03.011

West JW, Patton DE, Scheuer T, Wang Y, Goldin AL, and Catterall WA. 1992. A cluster of hydrophobic amino acid residues required for fast $\mathrm{Na}^{+}$channel inactivation. Proceedings of the National Academy of Sciences of the United States of America 89:10910-10914.

Westerfield M, Moore JW, Kim YS, and Padilla M. 1977. How Gymnodinium breve red tide toxin(s) produces repetitive firing in squid axons. American Journal of Physiology 232:23-29.

Yang N, and Horn R. 1995. Evidence for voltage-dependent S4 movement in sodium channels. Neuron 15:213-218. 10.1016/0896-6273(95)90078-0

Yue L, Navarro B, Ren D, Ramos A, and Clapham DE. 2002. The cation selectivity filter of the bacterial sodium channel, NaChBac. The Journal of General Physiology 120:845-853. 10.1085/jgp.20028699 
Figure 1

Effect of $\mathrm{PbTx}-3$ on 0 . sinensis membrane potential

Representative traces show free-running membrane potential monitored over 15 min following additions of (A) ASW and (B, C) $1 \mu \mathrm{M}$ PbTx-3 indicated by arrows. No significant change in pattern of membrane potential was observed ( $n=4$ and 12 cells for control and treatments, respectively) for either cells exhibiting spontaneous oscillations (A, B) or quiescent membrane potential (C).
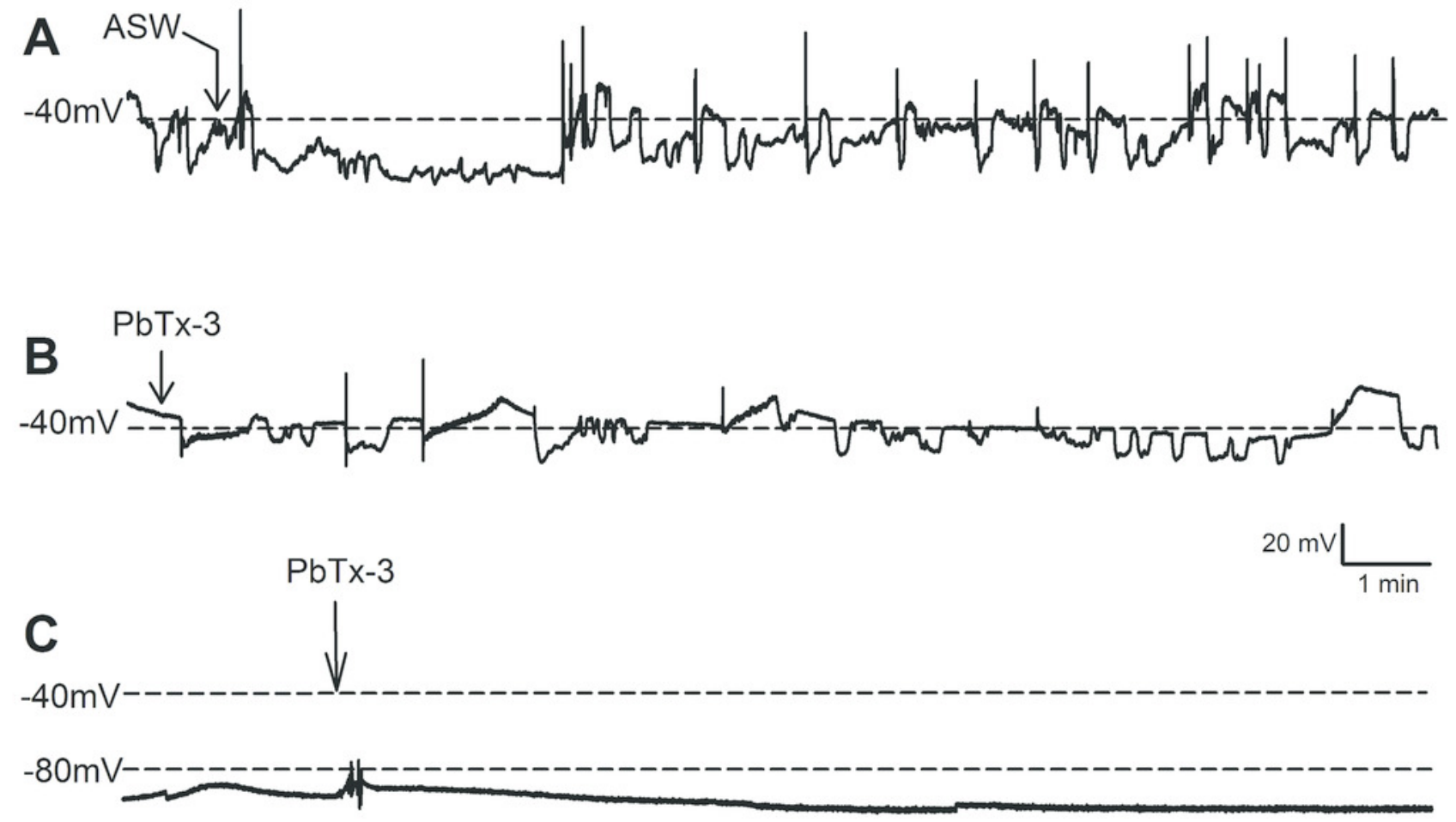


\section{Figure 2}

\section{Effects of PbTx-3 on 0 . sinensis voltage activated currents}

(A) Representative ion currents evoked in response to depolarizing voltage clamp pulses under control conditions, after 15 min treatment of bolus ASW ( $n=7$ cells tested) and after treatment with $1 \mu \mathrm{M}$ PbTx-3 for 15 min showing a clear decline in both peak inward and delayed outward currents ( $n=14$ cells tested). (B) Detail of fast inactivating inward current evoked by voltage clamp pulse from - $-100 \mathrm{mV}$ to $-60 \mathrm{mV}$ before and after $1 \mu \mathrm{M}$ PbTx-3 perfusion. (C) Combined current-voltage plot for PbTx perfusion experiments in which average peak inward current was plotted as a function of membrane voltage in the absence (black circles) and presence of $1 \mu \mathrm{M} \mathrm{PbTx}-3$ (orange circles), and peak outward current in the absence (black triangles) and presence of $1 \mu \mathrm{M} \mathrm{PbTx}-3$ (orange triangles). $n=14$ experiments. Standard error bars are indicated. 


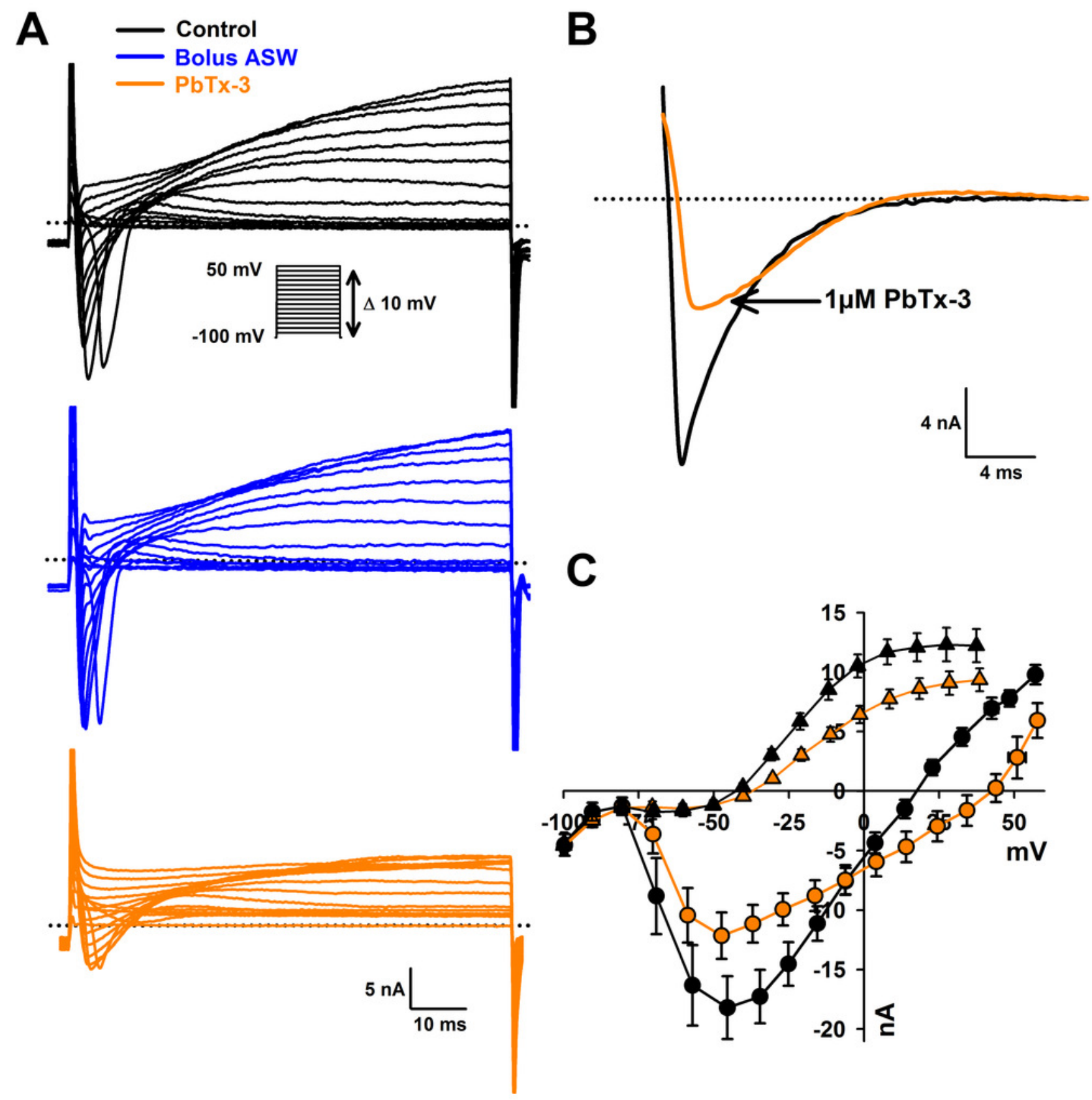




\section{Figure 3}

Activation and inactivation properties of diatom $\mathrm{Na}^{+} / \mathrm{Ca}^{2+}$ currents in the presence of PbTx-3

(A) Voltage activation was determined by calculating the peak $\mathrm{Na}^{+} / \mathrm{Ca}^{2+}$ conductance (g) for each voltage pulse and normalized to the maximum conductance. The resulting $g-V$ values were fitted to a Boltzmann distribution. Half activation voltage $\left(V_{h}\right.$, the voltage stimulus that evoked $50 \%$ of the peak current) was not significantly affected by $1 \mu \mathrm{M} \mathrm{PbTx}-3$ (orange circles). (B) Steady state voltage inactivation was determined using a series of depolarizing voltage pre-pulses from a holding voltage of $-100 \mathrm{mV}$ were applied before evoking maximal inward currents by a test pulse to $-60 \mathrm{mV}$. The average peak currents in response to test pulses were normalized to the maximum peak current and fitted to a Boltzmann curve. Half inactivation voltage $\left(V_{\text {inact }}\right)$ was the pre-pulse voltage at which half the peak current was suppressed. There was a small but significant ( $p<0.05$, Students T-test) positive shift in the inactivation in the presence of $\mathrm{PbTx}-3$ (orange circles) compared to controls (black circles). (C) Recovery from inactivation was measured using a double pulse protocol under control conditions in which the first voltage evoked a maximal inward $\mathrm{Na}^{+} / \mathrm{Ca}^{2+}$ current followed by a variable time interval $(\Delta \mathrm{ms})$, after which a second depolarization pulse was applied. The peak response to the second voltage clamp pulse after a 2 ms delay was less than $10 \%$ of the peak, demonstrating the majority of VCGs were inactivated. Delay of 10-20 ms was generally required for the current to be fully recovered. The same recovery from inactivation protocol was applied to the same cell after $1 \mu \mathrm{M}$ PbTx-3 treatment showed a similar pattern of recovery although overall a decreased peak current amplitude as demonstrated in Fig. 2 . Capacity transients are removed from the current traces for clarity. A recovery from inactivation plot where the second peak current response is expressed as a \% of the first and plotted against the pulse time interval. Control (black circles) and $1 \mu \mathrm{M} \mathrm{PbTx}-3$ (orange circles) curves were fit with an exponential with no significant difference in the time 
constant. In all experimental trials $(n=14)$ the standard error bars are indicated.
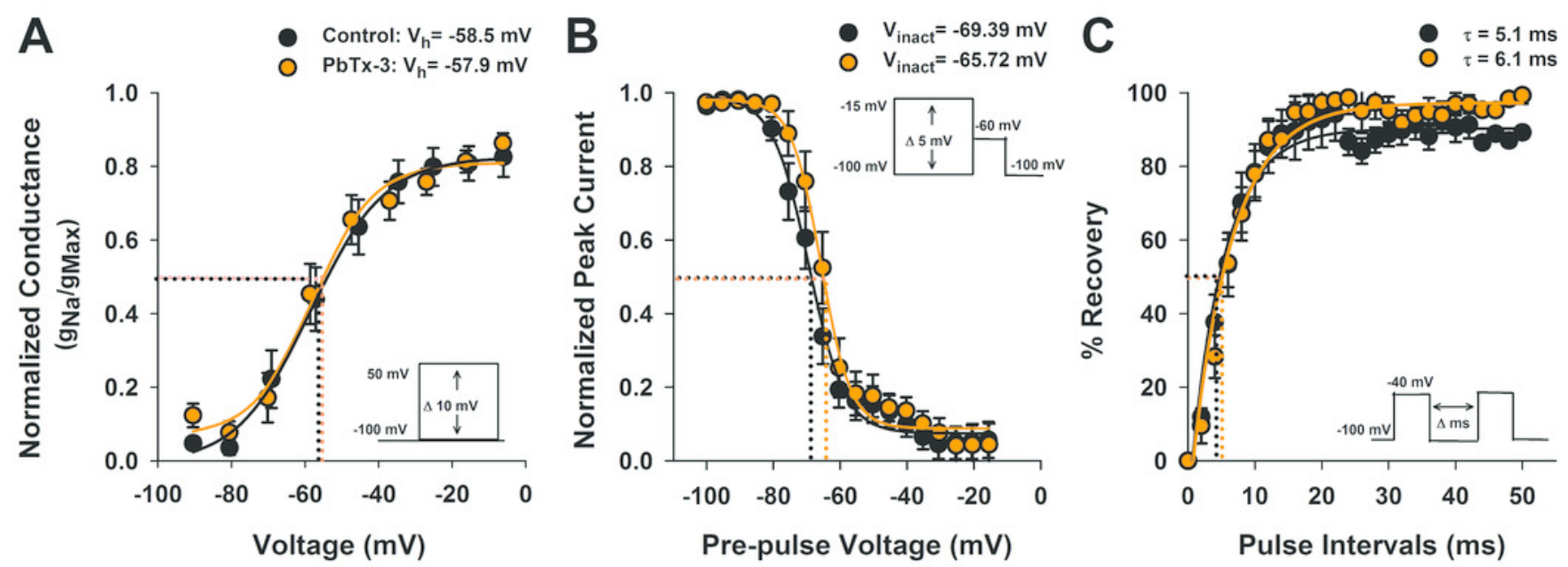


\section{Figure 4}

\section{Sequence analysis of diatom $\mathrm{Na}^{+} / \mathrm{Ca}^{2+} \mathrm{VGCs}$ and $\mathrm{PbTx}$ binding site}

Representative single domain $\mathrm{Na}^{+} / \mathrm{Ca}^{2+}$ VGCs were selected from bacteria ( $\mathrm{NaChBac}$ ), and the diatom $\mathrm{O}$. sinensis. Four-domain channels are represented by the diatom $T$. pseudonana, dinoflagellate $K$. brevis, and mammalian $\mathrm{Na}_{v} 1.2$. The major trans-membrane spanning domains colored in blue. The site of the high field strength residue within the selectivity filter is indicated by a letter above each domain. In the 4-domain VGCs, the inactivation gate is indicated and the PbTx binding site previously identified in $\mathrm{Na}_{v} 1.2$ are highlighted in orange. (B) A multiple sequence alignment of the diatom one-domain channels obtained by BLAST searches with the bacterial channel NaChBac. The selectivity filter is indicated in light blue and the high field strength residue in teal. (C) Multiple sequence alignment of eukaryote 4 domain $\mathrm{Na}^{+}$VGCs highlighting the two PbTx-3 binding regions characterized by Trainer et al. (1994). Conserved residues are labeled in orange (80-100\% similarity) and yellow (80-60\% similarity). Highly conserved residues of the upstream transmembrane segments are colored based on similarity using the Blosum62 score matrix (Henikoff \& Henikoff, 1992) , where darker shades of grey are more similar. Sequences were obtained from NCBI and iMicrobe databases with further details provided in Table S1.
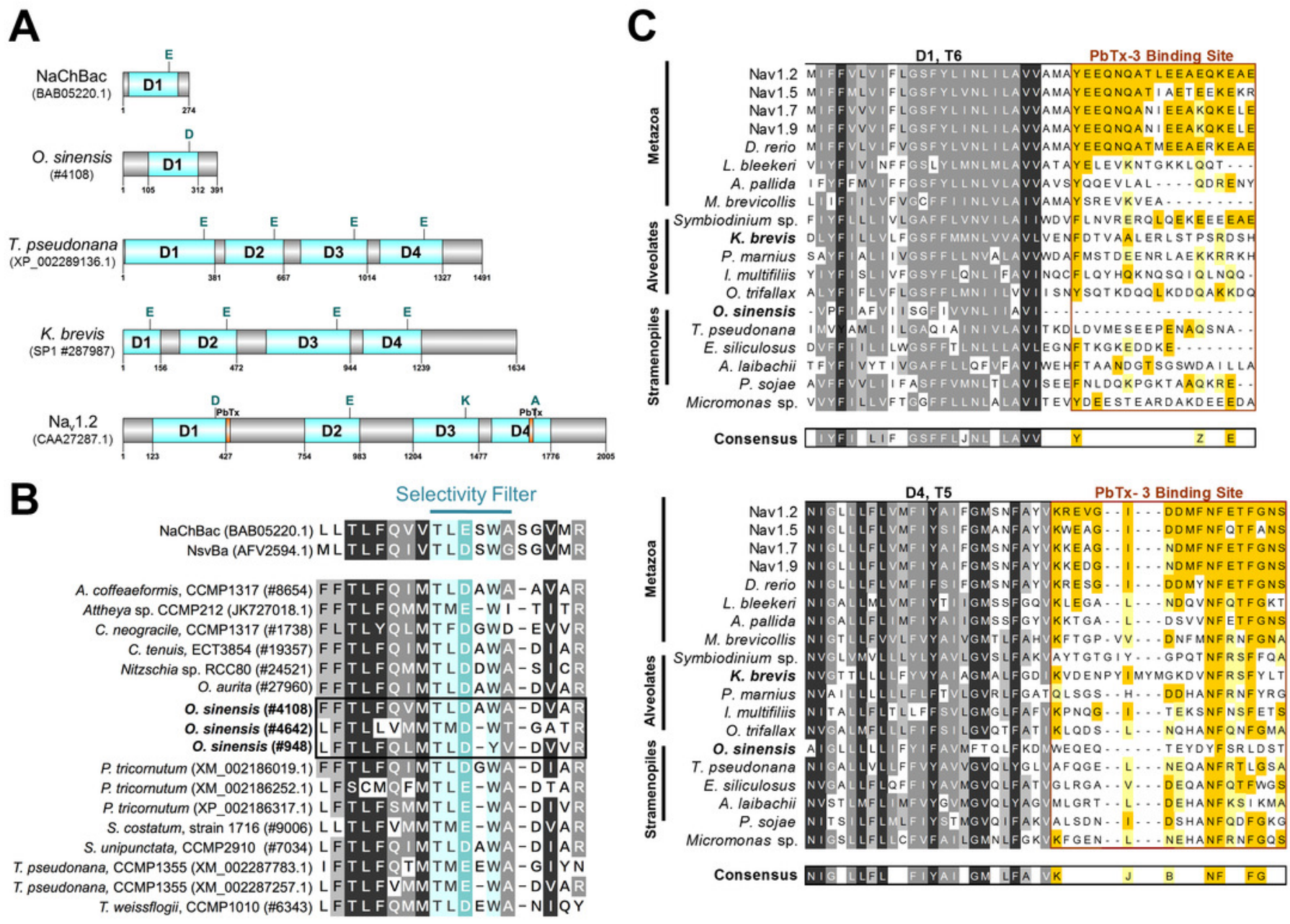